Article

\title{
Effect of Yttrium Addition on Glass-Forming Ability and Magnetic Properties of Fe-Co-B-Si-Nb Bulk Metallic Glass
}

\author{
Teruo Bitoh * and Dai Watanabe \\ Department of Machine Intelligence and Systems Engineering, Faculty of Systems Science \\ and Technology, Akita Prefectural University, Yurihonjo 015-0055, Japan; \\ E-Mail: b12a084@akita-pu.ac.jp
}

* Author to whom correspondence should be addressed; E-Mail: teruo_bitoh@akita-pu.ac.jp; Tel.: +81-184-27-2161; Fax: +81-184-27-2188.

Academic Editors: K. C. Chan and Jordi Sort Viñas

Received: 28 April 2015 / Accepted: 23 June 2015 / Published: 29 June 2015

\begin{abstract}
The glass-forming ability (GFA) and the magnetic properties of the $\left[\left(\mathrm{Fe}_{0.5} \mathrm{Co} 0.5\right)_{0.75} \mathrm{~B}_{0.20} \mathrm{Si}_{0.05}\right] 96 \mathrm{Nb}_{4}-x \mathrm{Y}_{x}$ bulk metallic glasses (BMGs) have been studied. The partial replacement of $\mathrm{Nb}$ by $\mathrm{Y}$ improves the thermal stability of the glass against crystallization. The saturation mass magnetization $\left(\sigma_{\mathrm{s}}\right)$ exhibits a maximum around 2 at. $\% \mathrm{Y}$, and the value of $\sigma_{\mathrm{s}}$ of the alloy with 2 at. $\% \mathrm{Y}$ is $6.5 \%$ larger than that of the Y-free alloy. The coercivity shows a tendency to decrease with increasing $\mathrm{Y}$ content. These results indicate that the partial replacement of $\mathrm{Nb}$ by $\mathrm{Y}$ in the $\mathrm{Fe}-\mathrm{Co}-\mathrm{B}-\mathrm{Si}-\mathrm{Nb}$ BMGs is useful to simultaneous achievement of high GFA, high $\sigma_{\mathrm{s}}$, and good soft magnetic properties.
\end{abstract}

Keywords: soft magnetic material; bulk metallic glass; iron-based alloy; magnetization; coercivity

\section{Introduction}

The Fe-based bulk metallic glasses (BMGs) are expected as a new class of soft magnetic materials with extremely low core losses [1]. The BMGs have large glass-forming ability (GFA) and, therefore, they can be used to prepare amorphous alloys with thicknesses of few millimeters by casting. Furthermore, the soft magnetic properties of the Fe-based BMGs are better than those of ordinary 
amorphous alloys which require extremely high cooling rate, typically $10^{5}-10^{6} \mathrm{~K} / \mathrm{s}$, for amorphous formation due to their low GFA [2-4].

One of the disadvantages of the Fe-based soft magnetic BMGs is the smaller saturation magnetization (typically $1.2 \mathrm{~T}$ or less) compared with the ordinary Fe-based amorphous alloys. The demands on soft magnetic materials include higher combined magnetization and permeability. In order to achieve high magnetization, it is necessary to reduce the contents of solute elements such as B, C, Si and P. However, the reduction of the solute elements content leads to a decrease of GFA.

Recently, we reported that the effect of replacement of $\mathrm{Nb}$ by $\mathrm{Y}$ on GFA and the magnetic properties of the $\left(\mathrm{Fe}_{0.8} \mathrm{Co}_{0.2}\right)_{96-x} \mathrm{~B}_{y} \mathrm{Si}_{1} \mathrm{Nb}_{3-x} \mathrm{Y}_{x}(y=15,17)$ alloys [5], which is close to the limit of the amorphous formation [6]. The results obtained in the study indicate that the partial replacement of $\mathrm{Nb}$ by $\mathrm{Y}$ in the $\mathrm{Fe}-\mathrm{Co}-\mathrm{B}-\mathrm{Si}-\mathrm{Nb}$ alloys is useful to simultaneous achievement of high GFA, high magnetization, and good soft magnetic properties. In the present study, we have investigated the effect of the replacement of $\mathrm{Nb}$ by $\mathrm{Y}$ on GFA and the magnetic properties of the $\left[\left(\mathrm{Fe}_{0.5} \mathrm{Co} 0.5\right)_{0.75} \mathrm{~B}_{0.20} \mathrm{Si}_{0.05}\right]_{96} \mathrm{Nb}_{4}$ alloy. Although this alloy has the same $\mathrm{Fe}-\mathrm{Co}-\mathrm{B}-\mathrm{Si}-\mathrm{Nb}$ system as the previous ones, the GFA is quite different. The present alloy system has a large GFA which enables us to produce rod specimens with $5 \mathrm{~mm}$ in diameter by $\mathrm{Cu}$-mold casting [7]. In addition, the alloy exhibits the rather high magnetization of $1.13 \mathrm{~T}$ as well as the good soft magnetic properties [8,9]. Therefore, this alloy has a possibility to be able to form magnetic cores into complicated shapes by casting or by superplastic deformation in supercooled liquid region.

\section{Materials and Methods}

The mother alloys with nominal composition of $\left[(\mathrm{Fe} 0.5 \mathrm{Co} 0.5)_{0.75} \mathrm{~B}_{0.20} \mathrm{Si}_{0.05}\right]{ }_{96} \mathrm{Nb}_{4-x} \mathrm{Y}_{x}$ were prepared as follows. First, the eutectic Fe-33.1 mass \% Y alloy was prepared by arc-melting the mixture of pure $\mathrm{Fe}(99.99 \%)$ and $\mathrm{Y}(99.9 \%)$ metals in an Ar atmosphere. Subsequently, the mixtures of pure Fe, Co (99.9\%), and $\mathrm{Nb}(99.9 \%)$ metals, pure B (99.5\%) and $\mathrm{Si}(99.999 \%)$ crystals, and the eutectic $\mathrm{Fe}-\mathrm{Y}$ alloy were melted by an arc furnace in an Ar atmosphere. The rapidly-solidified ribbons with approximately $1 \mathrm{~mm}$ in width and $30 \mu \mathrm{m}$ in thickness were prepared by a single-roller melt-spinning apparatus with a $\mathrm{Cu}$ wheel in an Ar atmosphere.

The structure of the specimens was examined by X-ray diffractometry (XRD, PANalytical, Almelo, The Netherlands) with $\mathrm{Cu} K_{\alpha}$ incident radiation. The thermal stability of the glass was investigated using a differential scanning calorimetry (DSC, NETZSCH-Gerätebau, Selb, Germany) during heating at various heating rates $(\beta)$ between 0.167 and $0.667 \mathrm{~K} / \mathrm{s}$. The saturation mass magnetization $\left(\sigma_{\mathrm{s}}\right)$ was measured with a magnetic balance in an applied magnetic field $(H)$ up to $800 \mathrm{kA} / \mathrm{m}$ at $296 \pm 3 \mathrm{~K}$. The hysteresis loops of the $70 \mathrm{~mm}$ long straight specimens were measured by a hysteresis loop tracer with a compensation coil under a maximum magnetic field of $10 \mathrm{kA} / \mathrm{m}$ at room temperature. The hysteresis loops and $\sigma_{\mathrm{s}}$ were measured for the five specimens cut from the same ribbons.

\section{Results and Discussion}

Figure 1 shows the XRD profiles of the as-quenched specimens $(x=0,2,4)$ taken from the free surface. All the profiles consist only of a halo which originates from an amorphous phase. The similar results were obtained by both the free and wheel-contacted surfaces of all the alloys. Figure 2 shows 
the glass-transition temperature $\left(T_{\mathrm{g}}\right)$ and the onset temperature of crystallization $\left(T_{x}\right)$ together with the supercooled liquid region $\left(\Delta T_{x}\right)$ that is defined as the temperature interval between $T_{\mathrm{g}}$ and $T_{x}$ as a function of $\mathrm{Y}$ content. All the alloys exhibit the distinct glass transition before crystallization. Both $T_{\mathrm{g}}$ and $T_{x}$ increase with increasing $\mathrm{Y}$ content. The super-cooled liquid region also increases with replacing $\mathrm{Nb}$ by $\mathrm{Y}$. The maximum value of $\Delta T_{x}$ is $47 \mathrm{~K}$ for $x=1$, which is $6 \mathrm{~K}$ larger than that of the Y-free alloy. The alloys with $x=2-3$ also show the larger $\Delta T_{x}$ than that of the Y-free alloy. However, $\Delta T_{x}$ remarkably decreased to $28 \mathrm{~K}$ when $\mathrm{Nb}$ is completely replaced by $\mathrm{Y}$.

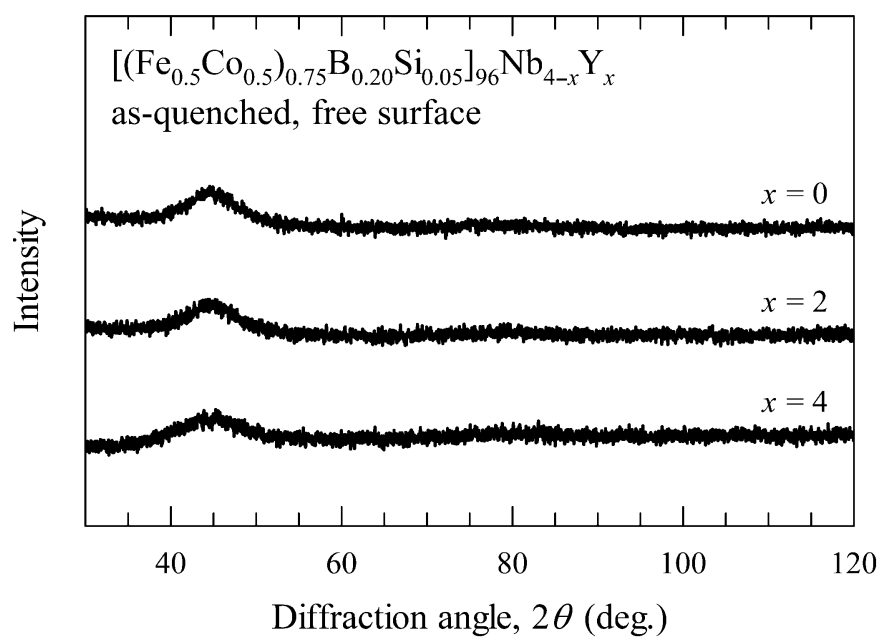

Figure 1. X-ray diffraction profiles of $\left[\left(\mathrm{Fe}_{0.5} \mathrm{Co} 0.5\right)_{0.75} \mathrm{~B}_{0.20} \mathrm{Si}_{0.05}\right] 96 \mathrm{Nb}_{4-x} \mathrm{Y}_{x}$ alloys taken from free surface in an as-quenched state.

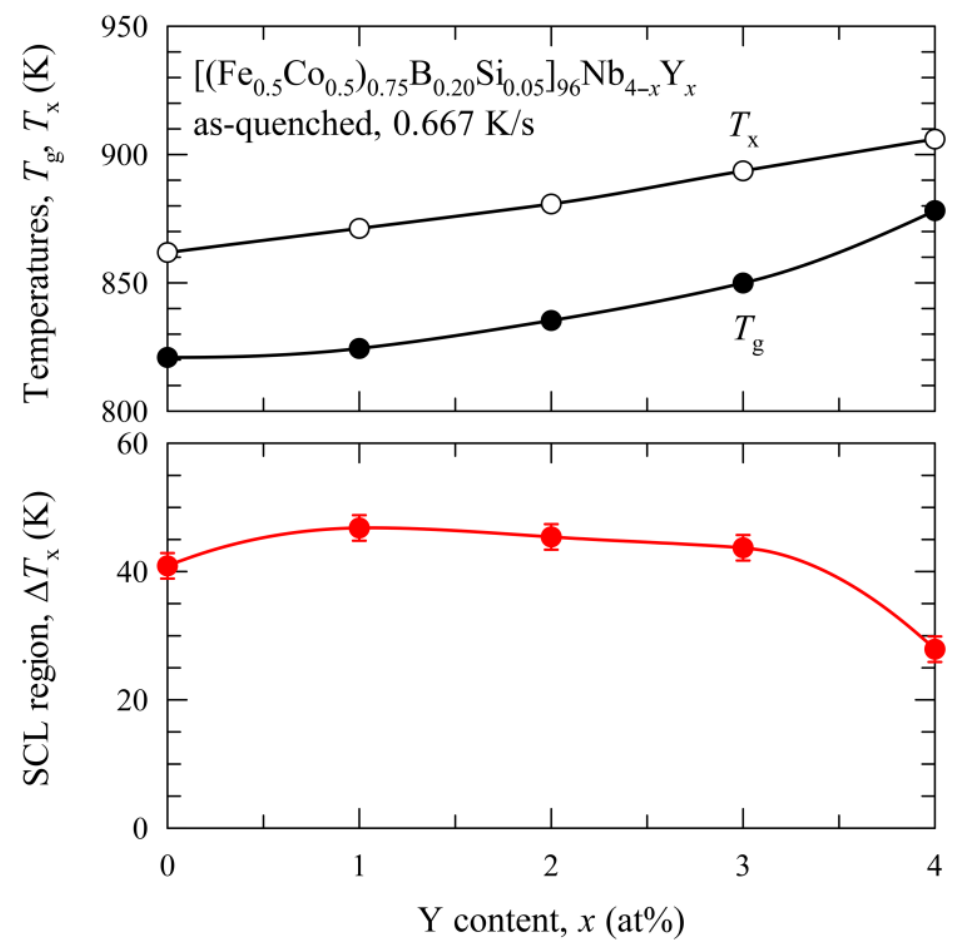

Figure 2. Glass-transition temperature $\left(T_{\mathrm{g}}\right)$, crystallization temperature $\left(T_{x}\right)$ and supercooled liquid (SCL) region $\left(\Delta T_{x}=T_{x}-T_{\mathrm{g}}\right)$ of $\left[\left(\mathrm{Fe}_{0.5} \mathrm{Co} 0.5\right)_{0.75} \mathrm{~B}_{0.20} \mathrm{Si}_{0.05}\right]_{96} \mathrm{Nb}_{4-x} \mathrm{Y}_{x}$ alloys as a function of $\mathrm{Y}$ content. 
In order to evaluate GFA of the alloys, the continuous heating transformation (CHT) curves have been derived by the Kissinger analysis in which $\ln \left(\beta / T_{\mathrm{p}}{ }^{2}\right) v s .1 / T_{\mathrm{p}}$ plot shows a linear relationship as shown in the following equation [10-12]:

$$
\ln \left(\frac{\beta}{T_{\mathrm{p}}^{2}}\right)=-\frac{E_{\mathrm{a}}}{R T_{\mathrm{p}}}+\ln \left(\frac{E_{\mathrm{a}} K_{0}}{R}\right)
$$

where $\beta$ is the heating rate, $T_{\mathrm{p}}$ is the peak temperature of the DSC curve (at which the transformation rate reaches maximum), $E_{\mathrm{a}}$ is the activation energy for nucleation and growth, $R$ is the gas constant, $K_{0}$ is the frequency factor, respectively. The values of $E_{\mathrm{a}}$ and $K_{0}$ can be obtained by the linear fit of the $\ln \left(\beta / T_{\mathrm{p}}^{2}\right)$ vs. $1 / T_{\mathrm{p}}$ plot. The CHT curves are derived by using the relationship between $T_{\mathrm{p}}$ and the heating time, $t_{\mathrm{h}}=\left(T_{\mathrm{p}}-298\right) / \beta$, where

$$
\beta=\frac{E_{\mathrm{a}} K_{0}}{R} T_{\mathrm{p}}^{2} \exp \left(-\frac{E_{\mathrm{a}}}{R T_{\mathrm{p}}}\right)
$$

In general, $T_{\mathrm{p}}$ is used in Kissinger analysis to investigate the maximum transformation rate during crystallization of glass. However, $T_{\mathrm{p}}$ can be replaced by $T_{x}$ (the onset temperature of crystallization) to calculate a CHT curve for the crystallization of glass, which indicates as actual starting point for the transformation [11,12]. Figures 3 and 4 show the heating rate dependence of $T_{x}$ and $\ln \left(\beta / T_{x}^{2}\right)$ vs. $1 / T_{x}$ plot, respectively. The values of the kinetics parameters required for calculation of the CHT curves are listed in Table 1. All the coefficients of determination $\left(R^{2}\right)$ for the linear regression of Figure 4 are larger than 0.9998 . Figure 5 shows the CHT curves that show the relationship between $T_{x}$ and corresponding heating time, $t_{\mathrm{h}}$. It should be noted that the boundary between the glass and the crystalline phases moves to the longer time side with increasing $\mathrm{Y}$ content. This means that the incubation time for crystallization is postponed, i.e., GFA is improved by the replacement of Nb by $\mathrm{Y}$.

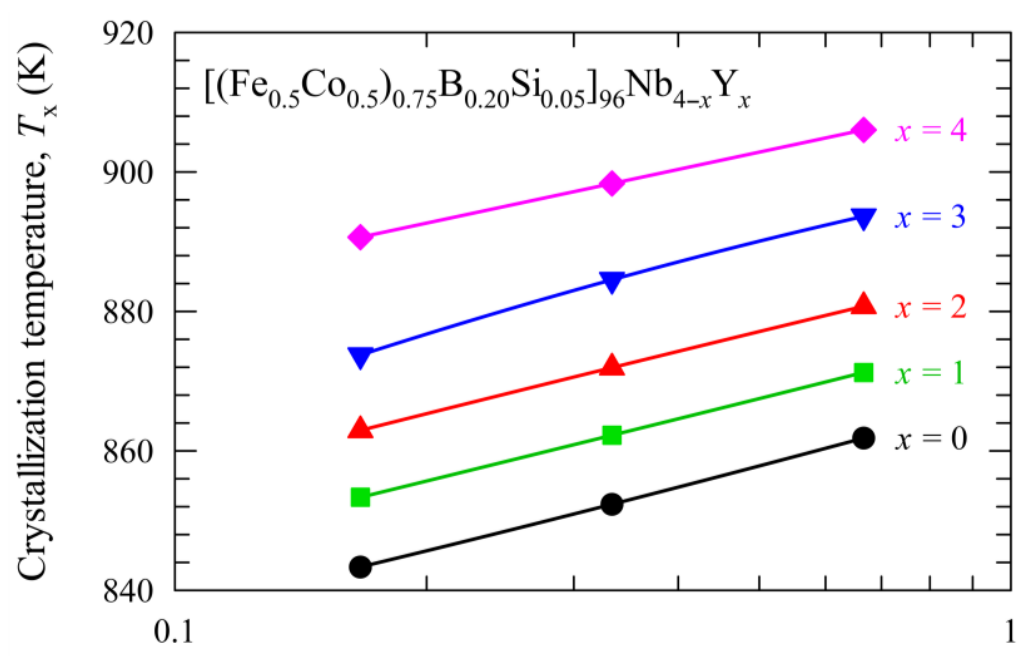

Heating rate, $\beta(\mathrm{K} / \mathrm{s})$

Figure 3. Heating rate $(\beta)$ dependence of the crystallization temperature $\left(T_{x}\right)$ of $\left[\left(\mathrm{Fe}_{0.5} \mathrm{Co} 0.5\right)_{0.75} \mathrm{~B}_{0.20} \mathrm{Si}_{0.05}\right]_{96} \mathrm{Nb}_{4-x} \mathrm{Y}_{x}$ alloy. 


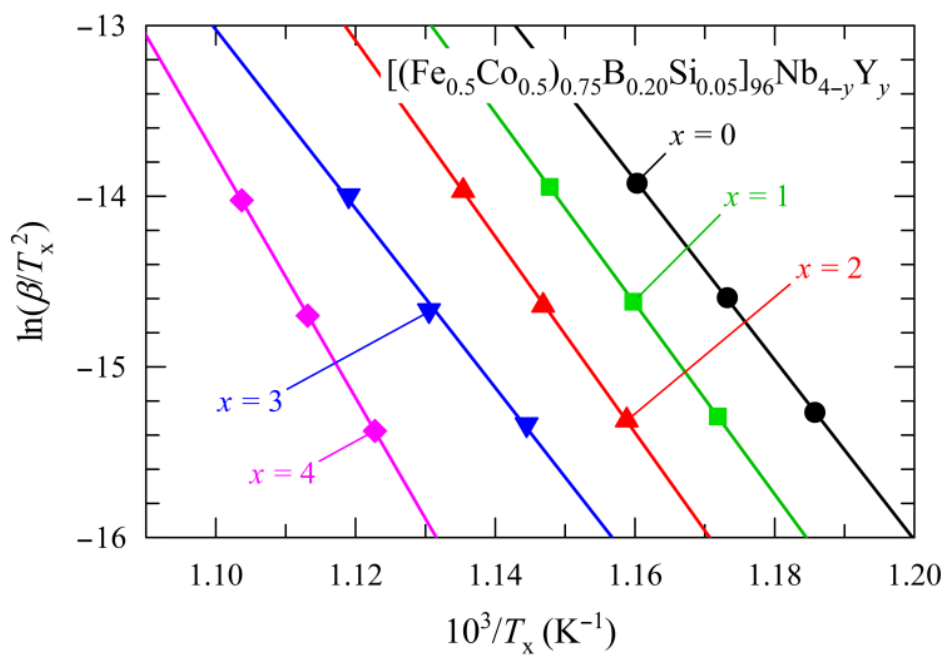

Figure 4. $\ln \left(\beta / T_{x}^{2}\right)$ vs. $1 / T_{x}$ plot for $\left[\left(\mathrm{Fe}_{0.5} \mathrm{Co} 0.5\right)_{0.75} \mathrm{~B}_{0.20} \mathrm{Si}_{0.05}\right] 96 \mathrm{Nb}_{4-x} \mathrm{Y}_{x}$ alloys.

Table 1. Kinetics parameters for onset crystallization temperatures for $\left[\left(\mathrm{Fe}_{0.5} \mathrm{Co} 0.5\right)_{0.75} \mathrm{~B}_{0.20} \mathrm{Si}_{0.05}\right]_{96} \mathrm{Nb}_{4-x} \mathrm{Y}_{x}$ alloys.

\begin{tabular}{cccccc}
\hline $\boldsymbol{x}$ & $\boldsymbol{T}_{\boldsymbol{x}} *(\mathbf{K})$ & $-\boldsymbol{E}_{\mathrm{a}} / \boldsymbol{R}\left(\mathbf{1 0} \mathbf{3}^{\mathbf{3}} \mathbf{K}\right)$ & $\boldsymbol{\operatorname { l n }}\left(\boldsymbol{E}_{\mathrm{a}} \boldsymbol{K}_{\mathbf{0}} / \boldsymbol{R}\right)$ & $\boldsymbol{E}_{\mathbf{a}}(\mathbf{k J} / \mathbf{m o l})$ & $\boldsymbol{K}_{\mathbf{0}}\left(\mathbf{s}^{\mathbf{- 1}}\right)$ \\
\hline 0 & 862 & 52.8 & 47.3 & 439 & $6.6 \times 10^{15}$ \\
1 & 871 & 55.9 & 50.2 & 464 & $1.1 \times 10^{17}$ \\
2 & 881 & 57.4 & 51.3 & 478 & $3.1 \times 10^{17}$ \\
3 & 894 & 58.8 & 51.9 & 489 & $5.6 \times 10^{17}$ \\
4 & 906 & 70.9 & 64.2 & 589 & $1.0 \times 10^{23}$ \\
\hline
\end{tabular}

* Measured at a heating rate of $0.667 \mathrm{~K} / \mathrm{s}$.

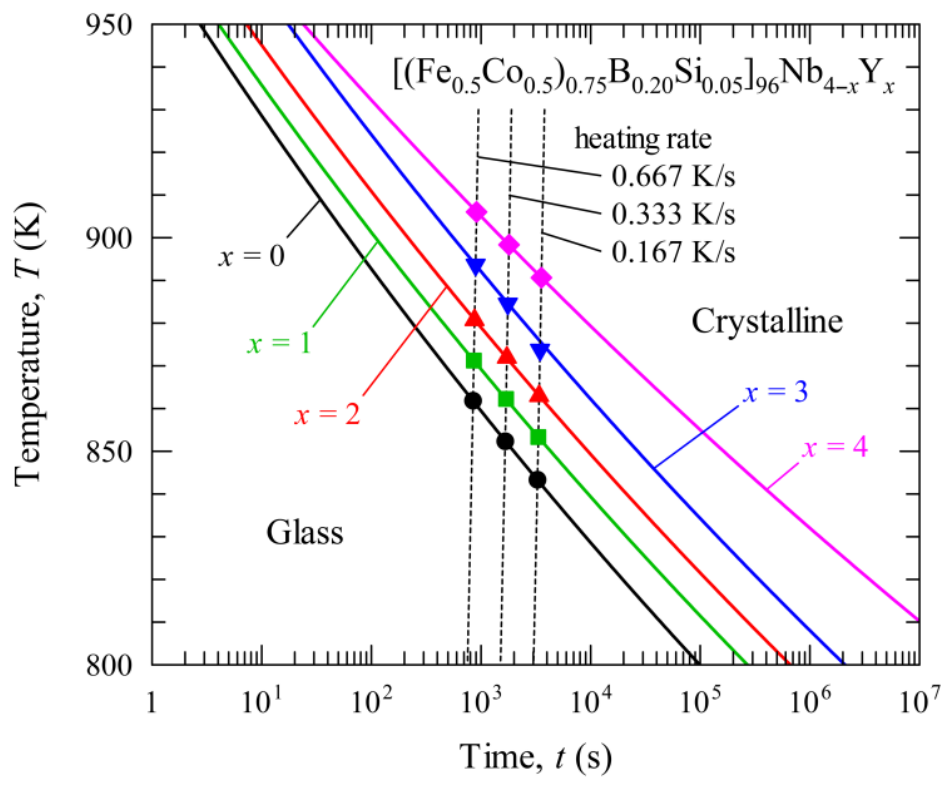

Figure 5. Continuous heating transformation (CHT) diagram of $\left[\left(\mathrm{Fe}_{0.5} \mathrm{Co} 0.5\right)_{0.75} \mathrm{~B}_{0.20} \mathrm{Si}_{0.05}\right]_{96} \mathrm{Nb}_{4-x} \mathrm{Y}_{x}$ alloys. The symbols represent the experimental values of the onset temperature of crystallization $\left(T_{x}\right)$ obtained by the differential scanning calorimetry (DSC) in the continuous heating. 
The stabilization of the amorphous phase can be achieved by increasing the atomic packing density in the amorphous phase. Yttrium has a large atomic radius of $181 \mathrm{pm}$, which is much larger than that of $\mathrm{Nb}$ (143 pm), Co (125 pm), Fe (124 pm), Si (117 pm), and B (83 pm) [13]. A large difference of the atomic radius between $\mathrm{Y}$ and $\mathrm{Fe}$ is favourable for increase the atomic packing density of the amorphous structure. It has been reported that Fe-TM-B (TM: transition metals) and Fe-Ln-B (Ln: lanthanides) type BMGs have unique network-like structure, in which triangular prisms consisting of Fe and B are connected to each other through glue atoms of TM or Ln [14,15]. If the atomic packing density increases, the atomic diffusion becomes more difficult. In addition, the much lower diffusivity of $\mathrm{Y}$ than $\mathrm{Nb}$ also contributes to the improvement of GFA. Therefore, it can be concluded that the improvement of GFA is brought by the replacement of $\mathrm{Nb}$ by $\mathrm{Y}$ with the larger radius than that of $\mathrm{Nb}$.

Figure 6 shows the saturation mass magnetization $\left(\sigma_{\mathrm{s}}\right)$ in an as-quenched state as a function of the $\mathrm{Y}$ content. As previously reported [5], the changes of $\sigma_{\mathrm{s}}$ are interesting. The magnetization exhibits a maximum around 2 at. \% Y. The cause of this phenomenon is unclear. However, we can point out a possibility of the influence of the nanoscale phase separation (NPS) or chemical short-range ordering (CSRO). It is known that the values of the magnetic moments depend on the local environment of Fe and Co atoms: the types of neighbors, the fluctuation of interatomic distance, and the average coordination number $[16,17]$. Therefore, the values of $\sigma_{s}$ will change according to degree of NPS or CSOR even if the contents of $\mathrm{Fe}$ and $\mathrm{Co}$ are fixed. The heat of mixing of $\mathrm{Y}$ and $\mathrm{Fe}, \mathrm{Co}$, and $\mathrm{Nb}$ atomic pairs are $-1,-22$, and $+30 \mathrm{~kJ} / \mathrm{mol}$, respectively $[18,19]$. Thus $\mathrm{Fe}-\mathrm{Y}$ is nearly ideal solution. However, $\mathrm{Y}$ atoms attract $\mathrm{Co}$ ones and repulse $\mathrm{Nb}$ ones. These interatomic attractive/repulsive forces may promote the formation of NPS or CSRO.

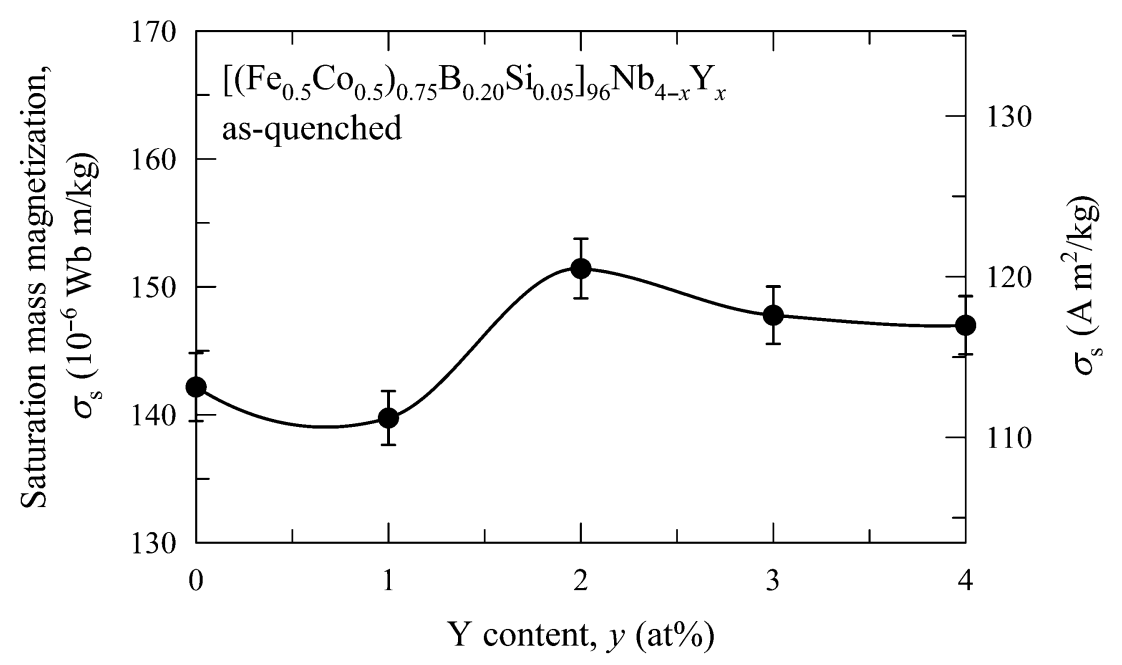

Figure 6. Saturation mass magnetization $\left(\sigma_{\mathrm{s}}\right)$ of $\left[\left(\mathrm{Fe}_{0.5} \mathrm{Co}_{0.5}\right)_{0.75} \mathrm{~B}_{0.20} \mathrm{Si}_{0.05}\right]_{96} \mathrm{Nb}_{4-x} \mathrm{Y}_{x}$ alloys in an as-quenched state as a function of $\mathrm{Y}$ content. The graph shows the mean value for the five specimens (closed circles). The error bars represent the $95 \%$ confidence limits $( \pm 2 \times$ standard errors).

Figure 7 shows the examples of the hysteresis loops of the alloy with $x=0,2$ in an as-quenched state. The hysteresis loops indicate that the alloys exhibit the good soft magnetic properties, i.e., low coercivity $\left(H_{\mathrm{c}}\right)$ and high permeability. Figure 8 shows $H_{\mathrm{c}}$ in an as-quenched state as a function of the $\mathrm{Y}$ 
content. The coercivity gradually decreases with increasing the $\mathrm{Y}$ content. This result suggests that the soft magnetic properties are improved by replacing $\mathrm{Nb}$ with $\mathrm{Y}$, which means the increase of GFA. This is considered to be due to the reduction of the free volume in an amorphous phase [2-4].

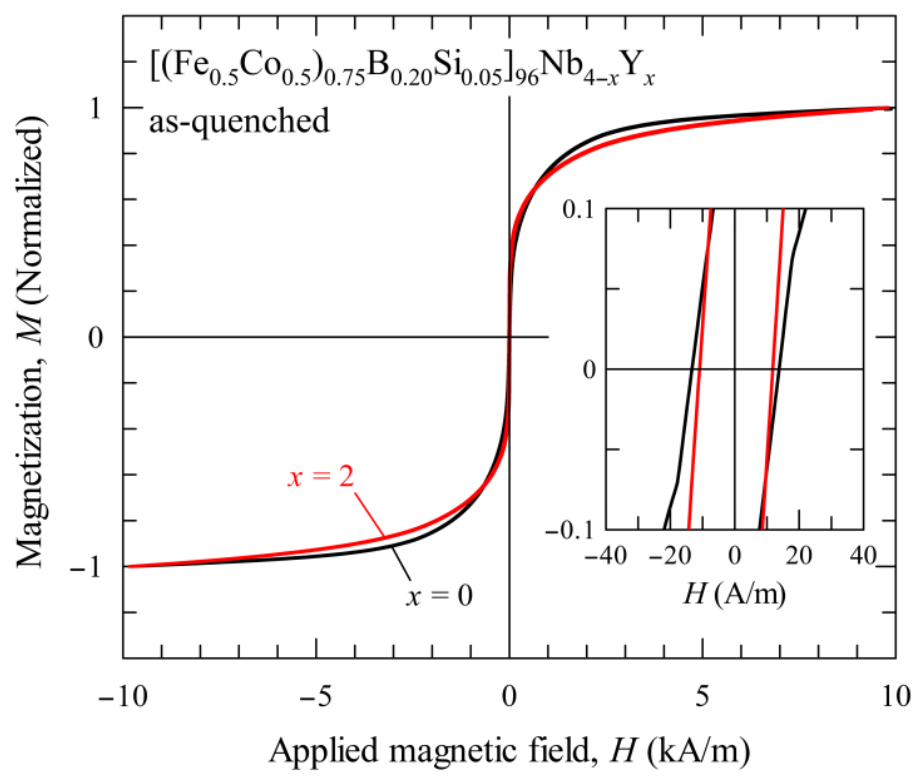

Figure 7. Hysteresis loops of $\left[\left(\mathrm{Fe}_{0.5} \mathrm{Co}_{0.5}\right)_{0.75} \mathrm{~B}_{0.20} \mathrm{Si}_{0.05}\right]_{96} \mathrm{Nb}_{4-x} \mathrm{Y}_{x}(x=0,2)$ alloys in an as-quenched state. Inset shows enlarged view near the origin.

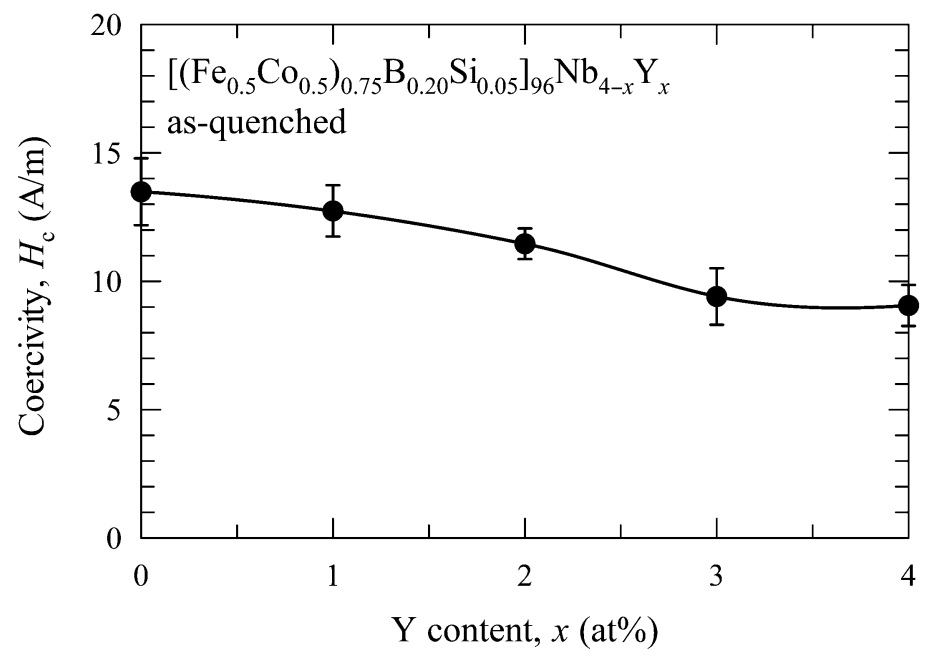

Figure 8. Coercivity $\left(H_{\mathrm{c}}\right)$ of $\left[\left(\mathrm{Fe}_{0.5} \mathrm{Co} 0.5\right)_{0.75} \mathrm{~B}_{0.20} \mathrm{Si}_{0.05}\right]_{96} \mathrm{Nb}_{4-x} \mathrm{Y}_{x}$ alloys in an as-quenched state as a function of $\mathrm{Y}$ content. The graph shows the mean value for the five specimens (closed circles). The error bars represent the $95 \%$ confidence limits $( \pm 2 \times$ standard errors).

\section{Conclusions}

It has been confirmed by the glass-forming ability (GFA) of the $\left[\left(\mathrm{Fe}_{0.5} \mathrm{Co}_{0.5}\right)_{0.75} \mathrm{~B}_{0.20} \mathrm{Si}_{0.05}\right]_{96} \mathrm{Nb}_{4-x} \mathrm{Y}_{x}$ bulk metallic glasses (BMGs) is improved by replacing $\mathrm{Nb}$ with $\mathrm{Y}$ by the continuous heating transformation (CHT) diagram. The improvement of GFA is brought by the replacement of Nb by $\mathrm{Y}$ with the larger radius than that of $\mathrm{Nb}$. 
The saturation mass magnetization $\left(\sigma_{\mathrm{s}}\right)$ exhibits a maximum around 2 at. $\%$ Y. The value of $\sigma_{\mathrm{s}}$ of the alloy with $x=2$ in an as-quenched state is $151 \times 10^{-6} \mathrm{~Wb} \mathrm{~m} / \mathrm{kg}$, which is $6.5 \%$ larger than that of the Y-free alloy. The coercivity $\left(H_{\mathrm{c}}\right)$ of the present alloys in an as-quenched state show a tendency to decrease with increasing Y content, which means an increase of GFA.

The results obtained in the present study indicate that the partial replacement of $\mathrm{Nb}$ by $\mathrm{Y}$ in the $\mathrm{Fe}-\mathrm{Co}-\mathrm{B}-\mathrm{Si}-\mathrm{Nb}$ BMGs is useful to simultaneous achievement of high GFA, high magnetization, and good soft magnetic properties. The good magnetic properties of the (Fe, $\mathrm{Co})-\mathrm{B}-\mathrm{Si}-(\mathrm{Nb}, \mathrm{Y}) \mathrm{BMGs}$ bring greater efficiency and miniaturization to magnetic devices.

\section{Acknowledgments}

This work was partly supported by Japan Society for the Promotion of Science (JSPS), Grant-in-Aid for Scientific Research (C) (KAKENHI), No. 24560806.

\section{Author Contributions}

Teruo Bitoh conceived and designed the experiments, and wrote the paper. Dai Watanabe performed the experiments and analyzed the data.

\section{Conflicts of Interest}

The authors declare no conflict of interest.

\section{References}

1. Inoue, A.; Takeuchi, A.; Shen, B. Formation and functional properties of Fe-based bulk glassy alloys. Mater. Trans. 2001, 42, 970-978.

2. Bitoh, T.; Makino, A.; Inoue, A. Origin of low coercivity of Fe-(Al, Ga)-(P, C, B, Si, Ge) bulk glassy alloys. Mater. Trans. 2003, 44, 2020-2024.

3. Bitoh, T.; Makino, A.; Inoue, A. Magnetization process and coercivity of $\mathrm{Fe}-(\mathrm{Al}, \mathrm{Ga})-(\mathrm{P}, \mathrm{C}, \mathrm{B}, \mathrm{Si})$ soft magnetic glassy alloys. Mater. Trans. 2004, 45, 1219-1227.

4. Bitoh, T.; Makino, A.; Inoue, A. Origin of low coercivity of $\left(\mathrm{Fe}_{0.75} \mathrm{~B}_{0.15} \mathrm{Si}_{0.10}\right)_{100-x} \mathrm{Nb}_{x}(x=1-4)$ glassy alloys. J. Appl. Phys. 2006, 99, 08F102.

5. Bitoh, T.; Kikuchi, S. Glass-forming ability and magnetic properties of $\left(\mathrm{Fe}_{0.80} \mathrm{Co}_{0.20}\right)_{96-x} \mathrm{~B}_{x} \mathrm{Si}_{1} \mathrm{Nb}_{3-y} \mathrm{Y}_{y}(x=15,17)$ amorphous alloys. IEEE Trans. Magn. 2014, 50, 1-5.

6. Ishikawa, T.; Tsubota, T.; Bitoh, T. Soft magnetic properties of ring-shaped $\mathrm{Fe}-\mathrm{Co}-\mathrm{B}-\mathrm{Si}-\mathrm{Nb}$ bulk metallic glasses. J. Magn. 2001, 16, 431-434.

7. Inoue, A.; Shen, B.L.; Chang, C.T. Super-high strength of over $4000 \mathrm{MPa}$ for Fe-based bulk glassy alloys in $\left[\left(\mathrm{Fe}_{1-x} \mathrm{Co}_{x}\right)_{0.75} \mathrm{~B}_{0.2} \mathrm{Si}_{0.05}\right]_{96} \mathrm{Nb}_{4}$ system. Acta Mater. 2004, 52, 4093-4099.

8. Bitoh, T.; Makino, A.; Inoue, A.; Greer, A.L. Large bulk soft magnetic $\left[\left(\mathrm{Fe}_{0.5} \mathrm{Co}_{0.5}\right)_{0.75} \mathrm{~B}_{0.20} \mathrm{Si}_{0.05}\right]_{96} \mathrm{Nb}_{4}$ glassy alloy prepared by $\mathrm{B}_{2} \mathrm{O}_{3}$ flux melting and water quenching. Appl. Phys. Lett. 2006, 88, 182510.

9. Bitoh, T.; Shibata, D. Improvement of soft magnetic properties $\left[\left(\mathrm{Fe}_{0.5} \mathrm{Co} 0.5\right)_{0.75} \mathrm{~B}_{0.20} \mathrm{Si}_{0.05}\right]_{96} \mathrm{Nb}_{4}$ bulk metallic glass by $\mathrm{B}_{2} \mathrm{O}_{3}$ flux melting. J. Appl. Phys. 2008, 103, 07E702. 
10. Kissinger, H.E. Variation of peak temperature with heating rate in differential thermal analysis. J. Res. Natl. Bur. Stand. 1956, 57, 217-221.

11. Louzguine, D.V.; Inoue, A. Comparison of the long-term thermal stability of various metallic glasses under continuous heating. Scr. Mater. 2002, 47, 887-891.

12. Kim, J.H.; Park, J.S.; Fleury, E.; Kim, W.T.; Kim, D.H. Effect of yttrium addition on thermal stability and glass forming ability in Fe-TM (Mn, Mo, Ni)-B ternary alloys. Mater. Trans. 2004, 45, 2770-2775.

13. Emsley, J. The Elements, 3rd ed.; Oxford University Press: Oxford, UK, 1998.

14. Nakamura, T.; Matsubara, E.; Imafuku, M.; Koshiba, H.; Inoue, A.; Waseda, Y. Structural study of amorphous $\mathrm{Fe}_{70} \mathrm{M}_{10} \mathrm{~B}_{20}(\mathrm{M}=\mathrm{Cr}, \mathrm{W}, \mathrm{Nb}, \mathrm{Zr}$ and $\mathrm{Hf})$ alloys by $\mathrm{X}$-ray diffraction. Mater. Trans. 2001, 42, 1530-1534.

15. Nakamura, T.; Koshiba, H.; Imafuku, M.; Inoue, A.; Matsubara, E. Determination of atomic sites of $\mathrm{Nb}$ dissolved in metastable $\mathrm{Fe}_{23} \mathrm{~B}_{6}$ phase. Mater. Trans. 2002, 43, 1918-1920.

16. O’Handley, R.C. Modern Magnetic Materials: Principles and Applications; Wiley-Interscience: New York, NY, USA, 1999; pp. 391-431.

17. Kakehashi, Y. Modern Theory of Magnetism in Metals and Alloys; Springer: Berlin, Germany, 2013; pp. 253-299.

18. De Boer, F.R.; Boom, R.; Mattens, W.C.M.; Miedema, A.R.; Niessen, A.K. Cohesion in Metals; North-Holland: Amsterdam, The Netherlands, 1988.

19. Takeuchi, A.; Inoue, A. Classification of bulk metallic glasses by atomic size difference, heat of mixing and period of constitute elements and its application to characterization of the main alloying element. Mater Trans. 2005, 46, 2817-2829.

(C) 2015 by the authors; licensee MDPI, Basel, Switzerland. This article is an open access article distributed under the terms and conditions of the Creative Commons Attribution license (http://creativecommons.org/licenses/by/4.0/). 